\title{
Consideraciones para la Atención de Urgencia Odontológica y Medidas Preventivas para COVID-19 (SARS-CoV 2)
}

\author{
Considerations for Emergency Dental Care and \\ Preventive Measures for COVID-19 (SARS-CoV 2)
}

\author{
Cristóbal Araya Salas
}

\begin{abstract}
ARAYA, S. C. Consideraciones para la atención de urgencia odontológica y medidas preventivas para COVID-19 (SARSCoV 2). Int. J. Odontostomat., 14(3):268-270, 2020.

RESUMEN: El siguiente artículo busca presentar diversas consideraciones para la atención odontológica a fin de disminuir riesgo de exposición al virus «Severe acute respiratory syndrome coronavirus 2 (SARS-CoV-2)» para el profesional odontólogo. La higiene y el lavado de manos tanto de profesionales como de pacientes, es considerado uno de los puntos más críticos para reducir el contagio. Los odontólogos también deben preferir diferir procedimientos electivos, en caso de atención de urgencias tomar medidas estrictas de bioseguridad para la protección de la piel y mucosas y considerar diferir en lo posible la atención odontológica en pacientes con signos y síntomas de Coronavirus (COVID-19).
\end{abstract}

PALABRAS CLAVE: Coronavirus, Odontología, COVID-19.

\section{INTRODUCCIÓN}

\section{Consideraciones Generales}

La siguiente revisión establece consideraciones en base a la atención odontológica en el contexto de la pandemia del Coronavirus disease (COVID-19) buscando disminuir riesgo en la exposición al virus severe acute respiratory syndrome coronavirus 2 (SARS-CoV2) para el profesional odontólogo. Previo a la atención odontológica se recomienda una adecuada categorización y decidir necesidad de realizar la atención de un paciente evaluando la posibilidad de diferir el procedimiento si este es de carácter electivo. En el caso de estar enfrentados a una urgencia odontológica, considerar el historial de contacto o viajes del paciente. Durante el proceso de triage se debe considerar medición y registro de temperatura del paciente. Para pacientes con registros de temperatura sobre $38^{\circ}$ con o sin presencia de síntomas como tos seca, coriza, odinofagia, insuficiencia respiratoria (Peng et al., 2020), el paciente se debe derivar a un centro asistencial para evaluación médica.

\section{Consideraciones Previas al procedimiento Dental}

Se ha descrito que el virus puede permanecer en superficies inertes por hasta incluso 9 días (Kampf et al., 2020). El lavado de manos es considerado uno de los puntos más críticos para reducir la contaminación, este lavado debe ser realizado por el profesional antes y después de cada atención, así como también por los pacientes, quienes al menos deben higienizar sus manos con alcohol gel o similar, previo y posterior a la atención. Los dentistas también deben tomar medidas estrictas de bioseguridad para la protección de piel y mucosas para ello se recomienda la utilización de mascarillas con filtro de partículas FFP2 o tipo N95, guantes de examen, lentes de protección o mascarillas con viseras faciales junto con delantal de aislamiento desechable (American Dental Association, 2020; Meng et al., 2020; Peng et al.), como medidas básicas en la atención de urgencia odontológica de pacientes positivos para COVID-19 o cuya confirmación este en estudio al momento de la consulta.

\footnotetext{
${ }^{1}$ Patólogo Bucomaxilofacial, Equipo de Cirugía Cabeza y Cuello, Instituto Nacional del Cáncer, Santiago, Chile.

${ }^{2}$ Odontólogo, Unidad de Emergencia, Hospital Barros Luco Trudeau, Santiago, Chile.

${ }^{3}$ Profesor Colaborador Claustro Académico Patología y Medicina Oral Universidad de Chile, Santiago, Chile.
} 


\section{Antisépticos y SARS-CoV-2}

La utilización de enjuagues antisépticos previo a la atención odontológica favorecería la disminución del virus en la cavidad oral (Meng et al.). La utilización de antisépticos de uso frecuente por odontólogos como clorhexidina no serían efectivos en la eliminación del SARS-CoV-2. Es por ello que la elección debe ser basándonos en un antiséptico que permita una adecuada disminución de la carga salival del virus sin generar daño en la mucosa oral. EI SARS-CoV-2 es vulnerable a la oxidación (Kampf et al.), el peróxido de hidrógeno, que incluso se encuentran fuera del uso rutinario hospitalario, se recomienda en una dilución al $1 \%$ (American Dental Association; Peng et al.). Para obtener $15 \mathrm{~mL}$ de enjuage, se puede utilizar $5 \mathrm{~mL}$ de peróxido de hidrógeno $10 \mathrm{Vol}$. adicionando $10 \mathrm{~mL}$ de agua destilada; también se ha descrito la utilización Povidona al 0,2\%. Estos antisépticos se han demostrado efectivos en la disminución de la carga viral salival y con baja posibilidad de complicaciones secundarias como estomatitis y úlceras de cavidad oral.

\section{Procedimientos Odontológicos}

En el caso de requerir estudio por imágenes para el diagnóstico de patologías del territorio maxilofacial se recomienda la utilización de técnicas Imageno-lógicas extraorales (Meng et al.) a fin de disminuir el contacto con la saliva como radiografía panorámica con utilización protector de plástico desechable para posicionador. Otra técnica que se ha indicado debido a que presenta baja exposición a fluidos es la tomografía computada en haz cónico donde no existe contacto de saliva con la máquina, sin embargo la indicación del estudio por imágenes en estos casos solo va a depender del requerimiento diagnóstico del clínico.

Deben evitarse los procedimientos que favorezcan la producción de aerosol como instrumental rotatorio, ultrasonido y la utilización de la jeringa triple. Para diagnósticos de patología pulpar o apical que requieran del uso de instrumental rotarorio el profesional debe preferir elementos de baja velocidad con mínima cantidad de irrigación así como la instalación de dique de goma y eyectores de saliva (Meng et al.; Peng et al.). La atención ideal también ha sido descrita en salas de procedimiento con presión negativa (Meng et al.) como pabellones. En el caso de poder programar la atención del paciente indicar la última hora de la agenda diaria, o realizar un adecuado aseo terminal del box de atención posterior a la atención.
Para extracciones dentales, se deben seguir las técnicas quirúrgicas según requiera la pieza dentaria a extraer, si el paciente presenta indicación de sutura estos deben ser de preferencia de carácter reabsorbible (Meng et al.) a modo de evitar retirarlo en procedimientos posteriores. Para la irrigación de alveolos dentales contar con las medidas de bioseguridad descritas previamente y aspiración, se puede además poner la mano libre del operador cubriendo parcialmente la boca del paciente como barrera al momento de irrigar para evitar contaminación de la región facial del operador.

Los casos de trauma maxilofacial deben presentar evaluación conjunta con profesional médico a fin de categorizar y determinar sospecha de infección de SARS-CoV-2 requiriendo incluso complementar el estudio mediante imágenes de tórax (Meng et al.) que permitan establecer sospecha de COVID-19 previo al resultado de las pruebas diagnósticas y estudios que presentan mayor sensibilidad pero que demandan mayor tiempo de espera como la reacción en cadena de la polimerasa en tiempo real (real-time PCR). Si se requiere de cirugía de control de daños, se debe considerar manejo de tejidos blandos faciales, desbridamientos bajo las medidas de irrigación presentadas previamente y suturas que sean necesarias acorde al tipo de lesiones que presente el paciente. De preferencia no indicar instalación de arcos de erich, ligaduras alámbricas o fijación intermaxilar tanto por el riesgo de contaminación hacia el operador como también por la necesidad manejo de la vía aérea que pudiese necesitar el paciente.

\section{Consideraciones Posterior al procedimiento}

Las áreas del box de atención deben limpiarse y desinfectarse con frecuencia, antisépticos como el hipoclorito de sodio en diluciones desde el 0,1\% durante 1 minuto (Kampf et al.) ha demostrado ser útil en la eliminación del COVID-19 en superficies inertes. La Organización mundial de la salud también recomienda la utilización de ethanol al $70 \%$ en superficies de menor tamaño (Kampf et al.; American Dental Association). Se debe incluir limpieza del sillón dental, salivero, lampara, brazos de mesa de trabajo, las manillas de las puertas, las sillas de operadores y los escritorios. Así también cobertura de elementos de las áreas limpias, sucias y administrativas que no se estén utilizando al momento de la atención. El aseo terminal del box de atención debe indicarse ante todo caso de paciente con estudio de COVID-19 pendiente y en casos confirmados. La eliminación de dese- 
chos orgánicos y utilizados en la atención de estos pacientes debe ser en bolsas de desechos amarillas de doble capa y los paquetes deben rotularse indicando contaminación de material por Coronavirus (Peng et al.)

\section{CONCLUSIONES}

La atención odontológica electiva debe ser diferida a fin de disminuir contagios y exposición del SARS-Cov-2. En caso de urgencia odontológica es fundamental obtener información de la historia médica de exposición y evaluar la presencia de síntomas como tos seca, coriza, odinofagia, fiebre, insuficiencia respiratoria, de estar presentes, el paciente debe ser referido a un servicio de urgencia hospitalaria para confirmación y manejo médico de COVID-19 en primera instancia y manejo odontológico conjunto según las medidas señaladas en esta revisión.

ARAYA, S. C. Considerations for emergency dental care and measures preventive for COVID-19 (SARS-CoV 2) . Int. J. Odontostomat., 14(3):268-270, 2020.

ABSTRACT: The following article aims to present various considerations for dental care in order to reduce the risk of exposure to the Severe acute respiratory syndrome Coronavirus 2 (SARS-CoV-2) virus for the dental professional. Hygiene and hand washing for both professionals and patients is considered one of the most critical points to reduce transmission. Dentists should favor elective procedures, and in cases of emergency follow strict biosecurity measures to protect the skin and mucosa. Professionals should also consider deferring dental care in patients with signs and symptoms of Coronavirus (COVID-19) for as long as possible.

KEY WORDS: Coronavirus, Dentistry, COVID-19.
Meng, L.; Hua, F. \& Bian, Z. Coronavirus Disease 2019 (COVID19): Emerging and Future Challenges for Dental and Oral Medicine. J. Dent. Res., 2020. Doi: 10.1177/0022034520914246. Disponible en: https://journals.sagepub.com/doi/full/10.1177/ 0022034520914246 ? url ver=Z39.882003\&rfr_id=ori:rid:crossref.org\&rfr_dat $=c r \_p u b \% 3 d p u b$ med\#articleCitationDownloadContainer

Peng, X.; Xu, X.; Li, Y.; Cheng, L.; Zhou, X. \& Ren, B. Transmission routes of 2019-nCoV and controls in dental practice. Int. J. Oral Sci., 12(1):9, 2020. Disponible en: http://www.nature.com/articles/ s41368-020-0075-9

Dirección para correspondencia:

Cristóbal Araya Salas

Patólogo Bucomaxilofacial

Unidad Cabeza y Cuello - INCancer

Santiago

CHILE

Email: cristobalarayasalas@gmail.com

Recibido : $16-03-2020$

Aceptado: 18-03-2020

\section{REFERENCIAS BIBLIOGRÁFICAS}

American Dental Association. Coronavirus Frequently Asked Questions. ADA Center for Professional Success. Sitio Web. American Dental Association, 2020. Disponible en: https:// success.ada.org/en/practice-management/patients/coronavirusfrequently-asked-questions

Kampf, G.; Todt, D.; Pfaender, S. \& Steinmann, E. Persistence of coronaviruses on inanimate surfaces and their inactivation with biocidal agents. J. Hosp. Infect., 104(3):246-51, 2020. Disponible en: https://www.journalofhospitalinfection.com/article/S01956701(20)30046-3/fulltext 